\title{
Experimental and Numerical Study to Enhance of Heat Transfer Coefficient in Air Flow Using Microchannel
}

\author{
Jalal M. Jalil Ghada A. Aziz Amjed A. Kadhim \\ Electromechanical Engineering Department, University of Technology, Baghdad, Iraq \\ jalamjail@gmail.com \\ aamjed387@gmail.com
}

\begin{abstract}
Experimental and numerical study of fluid flow and heat transfer in microchannel airflow is investigated. The study covers changing the cooling of micro-channel for the velocities and heater powers. The dimensions of the microchannel were, length $=0.1 \mathrm{~m}$, width $=0.001 \mathrm{~m}$, height $=0.0005 \mathrm{~m}$. The experimental and numerical results were compared with the previous paper for velocities up to $20 \mathrm{~m} / \mathrm{s}$ and heater powers up to $5 \mathrm{~W}$ and the comparison was acceptable. In this paper, the results were extended numerically for velocities up to $60 \mathrm{~m} / \mathrm{s}$. The numerical solution used finite volume (SIMPLE algorithm) to solve Navier Stokes equations (continuity, momentum and energy). The results show that the heat transfer coefficient increases up to $220 \mathrm{~W} / \mathrm{m}^{2}{ }^{\circ} \mathrm{C}$ for velocity $60 \mathrm{~m} / \mathrm{s}$.
\end{abstract}

Keywords: - Rectangular channel, Micro-channel, CFD, 3D Simulation, Heat transfer coefficient.

\section{Nomenclature}

\begin{tabular}{|c|c|c|}
\hline $\mathrm{cp}$ & specific heat $\mathrm{J} /(\mathrm{kg} \mathrm{K})$ & $\mathrm{W}_{\mathrm{ch}} \quad$ channel width $(\mathrm{m})$ \\
\hline $\mathrm{D}_{\mathrm{H}}$ & hydraulic diameter (m) & cross-sectional area of the flow $\left(\mathrm{m}^{2}\right)$ \\
\hline $\mathrm{H}_{\mathrm{ch}}$ & channel height (m) & wetted perimeter \\
\hline $\mathrm{H}_{\text {H.E }}$ & exchanger height (m) & heat exchanger effectiveness \\
\hline $\mathrm{K}$ & thermal conductivity $(\mathrm{W} / \mathrm{m} \mathrm{K})$ & dynamic viscosity (Pa.s) \\
\hline $\mathrm{L}$ & channel length (m) & density $\left(\mathrm{kg} / \mathrm{m}^{3}\right)$ \\
\hline$M$ & mass flow rate $(\mathrm{kg} / \mathrm{s})$ & $\alpha=\mathrm{H} / \mathrm{W}$ aspect ratio \\
\hline Q & heat transfer rate $(\mathrm{W})$ & $\mathrm{T}_{\text {out}}, \mathrm{T}_{\text {in }}$ outlet and inlet air Temperature, $\left({ }^{\circ} \mathrm{C}\right)$ \\
\hline $\mathrm{T}$ & temperature $\left({ }^{\mathrm{O}} \mathrm{C}\right)$ & kinematic viscosity of air $\left(\mathrm{m}^{2} / \mathrm{s}\right)$ \\
\hline $\mathrm{t}_{\mathrm{s}}$ & separating wall thickness (m) & axial coordinates $(\mathrm{m})$ \\
\hline $\mathrm{U}$ & $\mathrm{x}$-component velocity (m/s) & horizontal coordinates $(\mathrm{m})$ \\
\hline $\mathrm{V}$ & $\mathrm{y}$-component velocity $(\mathrm{m} / \mathrm{s})$ & vertical coordinates $(\mathrm{m})$ \\
\hline $\mathrm{W}$ & z-component velocity $(\mathrm{m} / \mathrm{s})$ & Control Volume \\
\hline VGs & vortex generator shapes & $\begin{array}{ll}\text { FVM } & \text { Finite Volume Method } \\
\text { T.H } & \text { thermal -hydraulic }\end{array}$ \\
\hline
\end{tabular}


Journal of University of Babylon for Engineering Sciences, Vol. (26), No. (7): 2018.

\section{Introduction}

The development in the techniques of micromachining in the recent years, especially in the microprocessor, it needs high accuracy and exact design of these techniques tends to have very small cooling system, which depends on work on the micro-channels techniques. Micro-channel is a device contains fluid channels with microscale dimensions; entrench in the surround solids with heating sources. Micro-channel cooling technology developed for the first time by [1]. Their distribution of water in the microfabricated channel, in silicon chip; they were to reach a thermal flow of $790 \mathrm{~W} / \mathrm{cm}^{2}$. [2]. Numerically looked into the actual circulation as well as heat move transfer within parallel circulation micro-channel heat exchangers with regard to thermally building laminar circulation within two parallel rectangles-shaped stations. [3]. investigated heat transfer of boiling flow with the two cooling systems R-245fa or R-134a in a microchannel, cold are evaporators, the range of rectangular micro-channels of HD $1.09,0.54 \mathrm{~mm}$ with countenance ratio 2.5 are considered. [4]. Studied a transfer of the heat characteristics in wavy micro-channel (WMCHS) with a rectangular cross-section with different wavy filed from 125 to $500 \mu \mathrm{m}$ were numerically scrupulous, on the basis (FVM) of the equations for the 3D. [5] Studied the effect of 3D, heat transfer and laminar flow during the micro-channel within a modern design (vortex generator (VGs, the best performance was found in the numbers Reynolds ( $\operatorname{Re}<600)$ a thermal-hydraulic(T.H) a radius of $30 \mu \mathrm{m}$ but they have hoped to get good values up to $150 \mu \mathrm{m}$. [6] Studied the flow boiling heat transfer, pressure drop in a copper multi-parallel microchannels heat sink using R134a as a working fluid with dimensions of $300 \mu \mathrm{m}$ wide, $700 \mu \mathrm{m}$ deep and $209 \mu \mathrm{m}$ separating wall thickness made of oxygen-free copper by CNC machining and was $20 \mathrm{~mm}$ long and $15 \mathrm{~mm}$ wide and hydraulic diameter of $420 \mu \mathrm{m}$. Wall heat flux $(5-120) \mathrm{kW} / \mathrm{m}^{2}$, mass flux $50-300 \mathrm{~kg} / \mathrm{m}^{2} \mathrm{~s}$ and system pressure 8.5-12.5 bar. [7] Studied design, fabrication, and experimental characterization of a novel additively manufactured air-water heat exchanger for dry cooling of power plants. The heat exchanger consists of manifold-microchannels on the air side and rectangular channels on the water side in a cross-flow configuration. By using additive manufacturing, the manifold-microchannel heat exchanger can be fabricated as a single component, which eliminates the assembly process. Three prototype heat exchangers were fabricated using direct metal laser sintering (DMLS) out of stainless-steel (SS17-4), titanium alloy (Ti64), and aluminum alloy (AlSi10Mg). [8] Studied single-phase heat transfer in a compact crossflow microchannel heat exchanger, with air flowing through the heat exchanger to remove heat from a closed-loop flow of refrigerant R245fa. The $1 \mathrm{~cm}^{3}$ heat exchanger was monolithically fabricated from a block of copper alloy, used microelectrical-discharge machining. Air carrying channels of diameter $520 \mathrm{~lm}$ were oriented in cross-flow to the refrigerant-carrying channels of size $2.0^{*} 0.5 \mathrm{~mm}^{2}$. High-speed air flowed with Reynolds number between $1.2^{*} 10^{\wedge}$ and $2.05^{*} 10^{\wedge}$, which corresponded to air speeds between 20 and $100 \mathrm{~m} / \mathrm{s}$,refrigerant flowed at Reynolds number between 1000 and 2300. In the present work, the experimental and numerical study will be utilized to founded the enhancement of transferring heat in micro-channel with air working fluid. Experimental and numerical investigation includes study changing of inlet air velocity and heater power. 
Journal of University of Babylon for Engineering Sciences, Vol. (26), No. (7): 2018.

\section{Experimental setup}

The experimental rig is photographically shown in Fig1. The present study has been conducted in the experimental preparation of a well-equipped single phase air flow, which is able to probe fluid flow and heat transfer characteristics of several air flows working in a wide range of operating conditions. With the control of the speed fan by using the Arduino circuit [9] as shown in Table 1. The lower base of the microchannel is of a rectangular shape. At first, connect the electrical accessories to electrical power. Run the blower to deploy the air in the gap of test, a mechanical gate was used to regulate the wanted of inlet air velocity. Operate the electric heaters and select input power limit which check by using Voltage Regulator. A steady state for identical temperature distribution is reached on the internal surface of micro-channel (which takes $60 \mathrm{~m}$ of the beginning of operation). Record the result of temperatures.

Table 1.1 Dimensions of the microchannel

\begin{tabular}{|c|c|c|}
\hline Description & Symbol & Value \\
\hline Channel Width & $w_{c h}$ & $1 \mathrm{~mm}$ \\
\hline Height of channel & $H_{c h}$ & $0.5 \mathrm{~mm}$ \\
\hline Length of channels & $\mathrm{L}$ & $100 \mathrm{~mm}$ \\
\hline Distant Between the channel & $\mathrm{Ww}$ & $3.5 \mathrm{~mm}$ \\
\hline Thickness of micro-channel base plat & $\mathrm{Hb}$ & $2 \mathrm{~mm}$ \\
\hline hydraulic diameter & $\mathrm{Dh}$ & $0.660 \mathrm{~mm}$ \\
\hline Number of channels & $\mathrm{N}$ & 10 \\
\hline
\end{tabular}

\section{Numerical work}

The physical model of the microchannel; air enters the channel from the left side with inlet temperature (Tin) which is assumed equal to the uniform room air temperature. Hot air exits from the right side at outlet temperature (Tout). The microchannel has a simple rectangular channel. The mathematical formulation of the fluid flow problem is governed by basic conservation of mass, momentum and energy equations. Laminar flow is beheld in the present study. The following assumptions have been made:

1- Three -dimensional of conservation equations.

2- Steady-state incompressible flow.

3- Conducted three-dimensional heat transfer through microchannels block.

4- Airflow in the channel has been considered Laminar.

5- All properties are estimated at an average temperature.

The governing Navier Stokes equations (continuity, momentum, and energy) in Cartesian Coordinates are as follows [10]. 
Journal of University of Babylon for Engineering Sciences, Vol. (26), No. (7): 2018.

Equation of continuity:

$$
\frac{\partial}{\partial x}(\rho u)+\frac{\partial}{\partial y}(\rho v)+\frac{\partial}{\partial z}(\rho w)=0
$$

Equations of momentum:

X-direction (U Momentum)

$$
\frac{\partial}{\partial x}(u u)+\frac{\partial}{\partial y}(u v)+\frac{\partial}{\partial z}(u w)-\frac{1}{\rho} \frac{\partial P}{\partial x}+\left(\frac{\partial^{2} u}{\partial x^{2}}+\frac{\partial^{2} u}{\partial y^{2}}+\frac{\partial^{2} u}{\partial z^{2}}\right)
$$

Y direction (V Momentum)

$$
\frac{\partial}{\partial x}(v u)+\frac{\partial}{\partial y}(v v)+\frac{\partial}{\partial z}(v w)=-\frac{1}{\rho} \frac{\partial P}{\partial y}+\left(\frac{\partial^{2} v}{\partial x^{2}}+\frac{\partial^{2} v}{\partial y^{2}}+\frac{\partial^{2} v}{\partial z^{2}}\right)
$$

$\mathrm{Z}$ direction (W Momentum)

$$
\frac{\partial}{\partial x}(u w)+\frac{\partial}{\partial y}(v w)+\frac{\partial}{\partial z}(w w)=-\frac{1}{\rho} \frac{\partial P}{\partial z}\left(\frac{\partial^{2} w}{\partial x^{2}}+\frac{\partial^{2} w}{\partial y^{2}}+\frac{\partial^{2} w}{\partial z^{2}}\right)
$$

Energy equation

$$
\frac{\partial}{\partial x}(u T)+\frac{\partial}{\partial y}(v T)+\frac{\partial}{\partial z}(w T)=\frac{k}{\rho C_{p}}\left(\frac{\partial^{2} T}{\partial x^{2}}+\frac{\partial^{2} T}{\partial y^{2}}+\frac{\partial^{2} T}{\partial z^{2}}\right)
$$

The heat flow in the $\mathrm{x}, \mathrm{y}$, and $\mathrm{z}$ directions may be calculated from Fourier equation [11]:

$$
\mathrm{q}_{-}=-k A \frac{\partial T}{\partial x}
$$

The CFD is analytic thought the systems that have fluid flow and heat transfer and connect flow phenomena by means of programs of computer based on simulation. The technicality was very powerful and expanded a wide range of various applications. The field in a Finite Volume Method is split into a number of non-overlapping CV's and take into considerations one CV'S a rounding each point in the grid. The differential equations are integrated over all CVs [12] [13]. The calculations of heat transfer, the hydraulic diameter and Reynolds number are calculated by $\mathrm{s}$

$$
\begin{aligned}
& D h=\frac{4(\text { free area })}{\text { watted perimeter }}=\frac{4 * w_{c h} * H_{c h}}{2 *\left(w_{c h}+H_{c h}\right)} \\
& R_{e}=\frac{\rho v d}{\mu}
\end{aligned}
$$


In order to calculate the convective heat flux in a single-phase flow, one must monitor the mass flow rate and measure the difference of outlet and inlet temperatures of air contained in the cooling System

$$
\begin{aligned}
Q= & m * C_{p} *\left(T_{\text {ain }}-T_{\text {aout })}\right. \\
& Q=m * C_{p} *\left(T_{\text {ain }}-T_{\text {aout }}\right) \text { (8)The aforementioned equation will provide the }
\end{aligned}
$$
basic tools for interpreting and better understanding the significance of the acquired data, where the averaged heat transfer coefficients was defined as:-

$$
h=\frac{Q}{A_{s} *\left(T_{w}-T_{b}\right)}
$$

Where

$$
A s=(2 H+2 W) L
$$

The channel wall temperature, $T w$, is assumed to be uniform and equal to the average of the readings from the six thermocouples located in the copper test section. The average heat transfer coefficient is calculated as follows:

$T_{b}($ Average bulk mean temperature $)=\frac{T_{\text {in }+T_{\text {out }}}}{2}$

The corresponding average Nusselt number is defined as

$$
N_{S}=\frac{h * D_{h}}{K}
$$

It is clear that if the velocity is defined at the scalar grid points, the pressure is not properly represented in the discretized momentum equation. A remedy for this problem is by using a staggered grid for the velocity components The field in Finite Volume Method is split into a number of non-overlapping CV's and take into considerations one CV'S a rounding each point in the grid. The differential equation is integrated over all CVs [12] [13]. The more attractive advantage of the CV formula is that the resolution is resulting would imply, that the integral conservation of quantities, like energy, mass and momentum are properly contented overall and any group of CVs and of course on the whole arithmetic scale. This prosperity is for each number of grid points, not only in the sense of a limiting .when the number of network points is large after that, even the coarse mesh solution displays exact full balance. Show Fig. 2 Control volume for u-velocity. It is clear that if the velocity is defined at the scalar grid points, the pressure is not properly represented in the discretized momentum equation. A remedy for this problem is by using a staggered grid for the velocity components. The scalar variables are stored at the main grid points, while the velocity components are stored at staggered grids (the velocities are defined at the faces of control volumes).

\section{Results and Discussion}

The experimental and numerical results are shown and discussed. In the experimental part (block micro-channels), the studied parameters are duct inlet air velocities $(2,5,7,12$, $20,40,60 \mathrm{~m} / \mathrm{s})$ in the channels, and the heater powers $(1,2,3,4$ and $5 \mathrm{~W})$. The inlet air velocity changed with fixed power for each case. The air inlet temperature of micro- 
channels is the cooled room temperature and is fixed at $25^{\circ} \mathrm{C}$. Fig. 3 shows the variation of air outlet temperature with inlet air velocity for different heater powers for experimental and numerical results. The difference seems acceptable. After this validation, the numerical results are extended, so the inlet velocity reached $60 \mathrm{~m} / \mathrm{s}$. Fig. 4 shows the variation of outlet temperature with inlet velocity up to $60 \mathrm{~m} / \mathrm{s}$ for various heater powers. Fig. 5 shows that, the heat transfer coefficient increases with increases in velocity reaching a value of $225 \mathrm{~W} / \mathrm{m}^{2}{ }^{\circ} \mathrm{C}$ at $60 \mathrm{~m} / \mathrm{s}$ and power heater $5 \mathrm{~W}$, which very high value for air flow. Fig. 6 gives isotherm contours of air flow through micro-channels. The inlet air of the microchannel has a constant temperature $\left(25^{\circ} \mathrm{C}\right)$. The temperature features are fully illustrated in the figure. The temperature of the flow increases, with $\mathrm{x}$ direction (flow direction) because of the hot walls. The flow of $20 \mathrm{~m} / \mathrm{s}$ have higher temperature then 40 $\mathrm{m} / \mathrm{s}$ then $60 \mathrm{~m} / \mathrm{s}$ because of the lower velocity. Fig. 7 gives the flow field of the flow through micro-channel at $U_{C h}=60 \mathrm{~m} / \mathrm{s}$. The developing of the boundary layer is clear in the figure. The outlet velocity seems fully developed.

\section{Conclusions}

1- The difference is about 2-3\% between experimental and the numerical results.

2- The outlet velocity seems fully developed in the exit.

3- The outlet air temperature from micro-channel is increased as velocity decreased.

4- The heat transfer coefficient reaches a value of $225 \mathrm{~W} / \mathrm{m}^{2}{ }^{\circ} \mathrm{C}$ at $60 \mathrm{~m} / \mathrm{s}$ and power heater $5 \mathrm{~W}$ and the heat is seems penetrating the core of the flow.

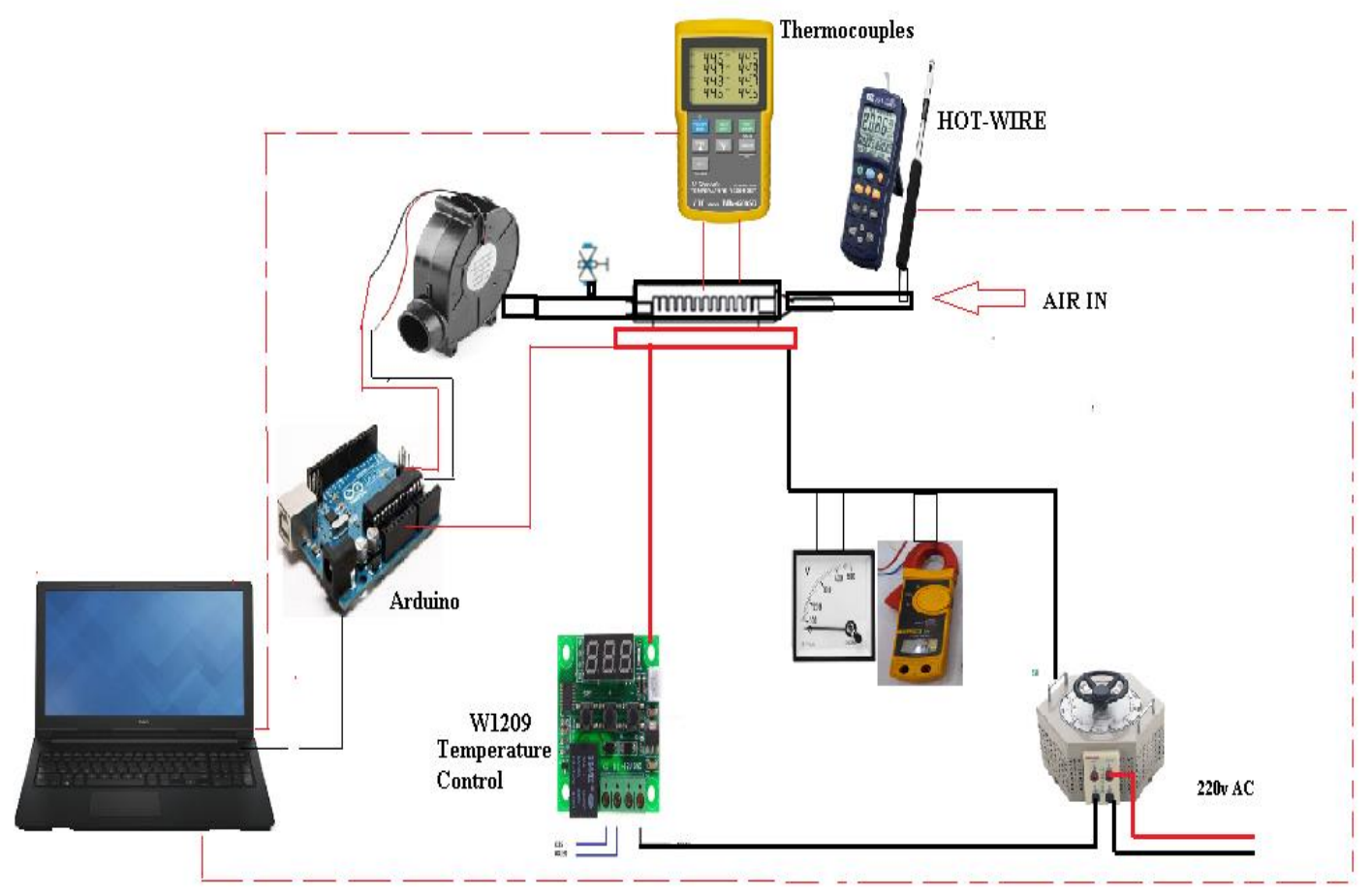

Fig. 1 Photograph of the Circuit 
Journal of University of Babylon for Engineering Sciences, Vol. (26), No. (7): 2018.

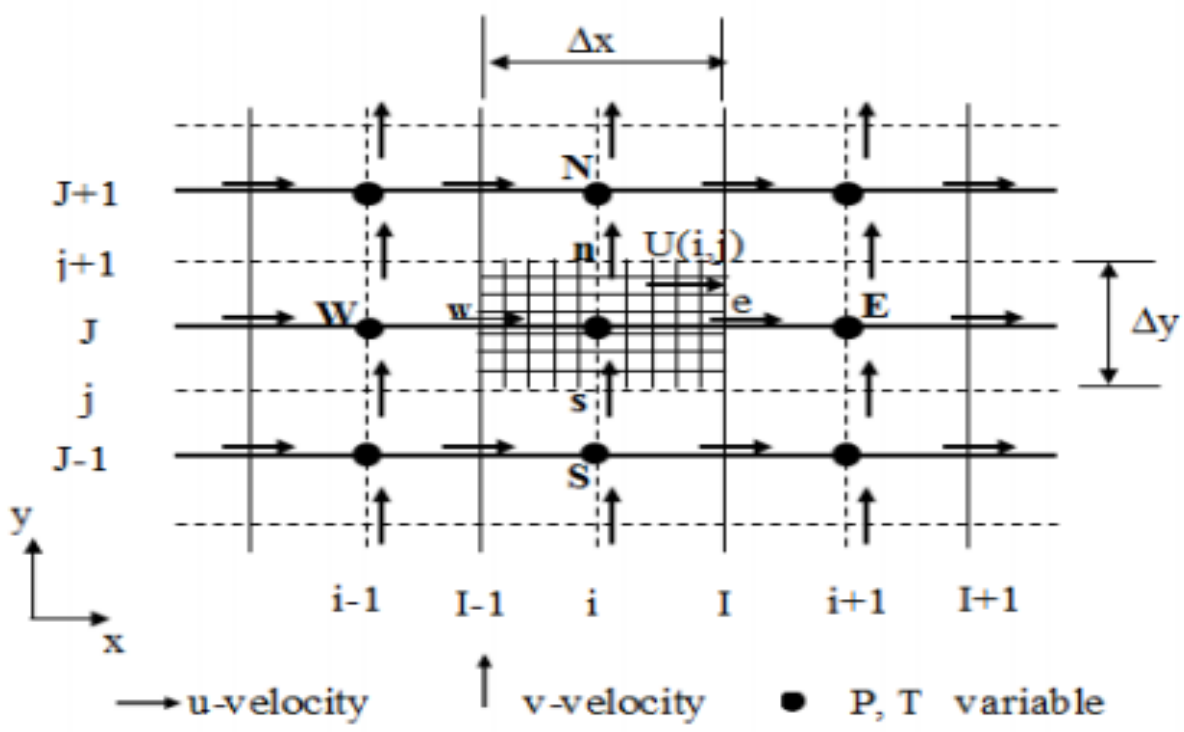

Fig. 2 Control volume for u-velocity

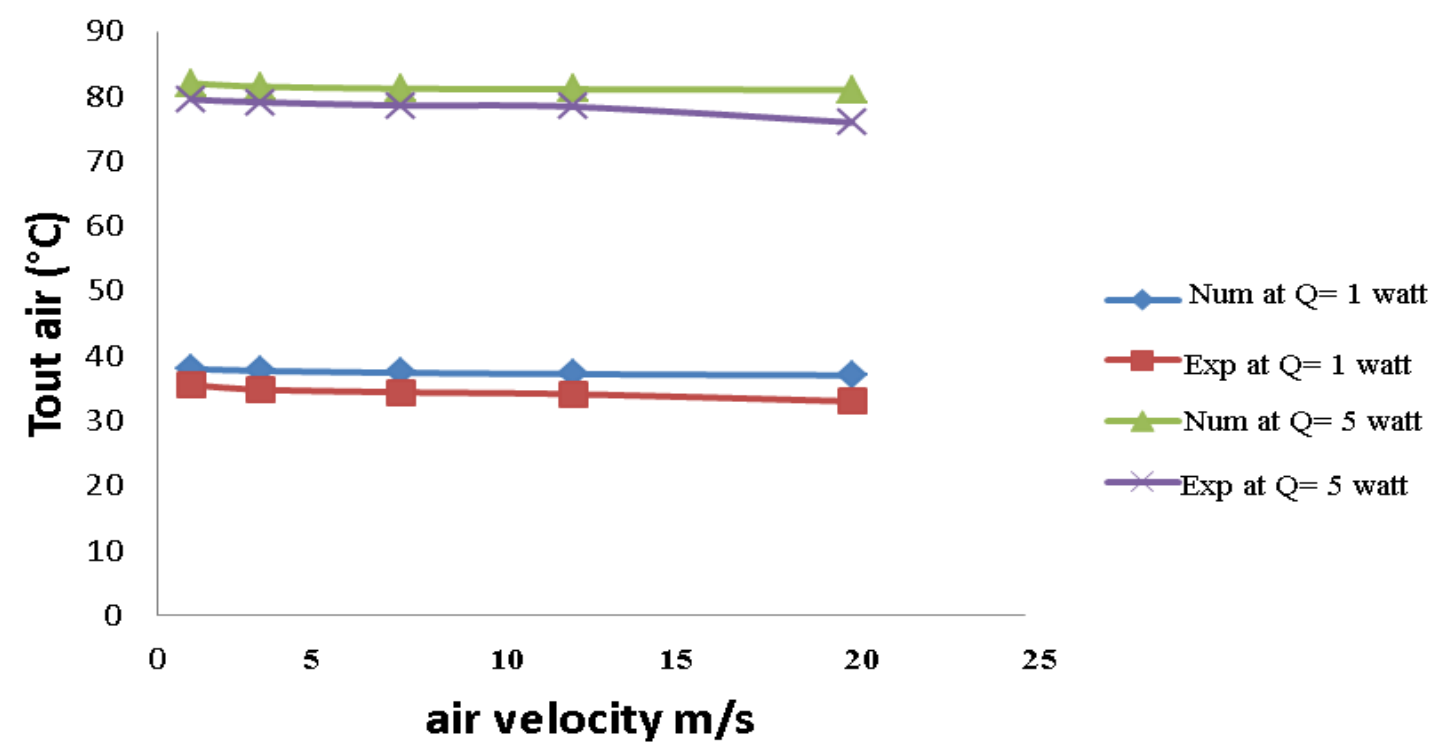

Fig. 3 The comparison between experiential and numerical results for the variation of air outlet temperature with inlet air velocities for various power heater 
Journal of University of Babylon for Engineering Sciences, Vol. (26), No. (7): 2018.

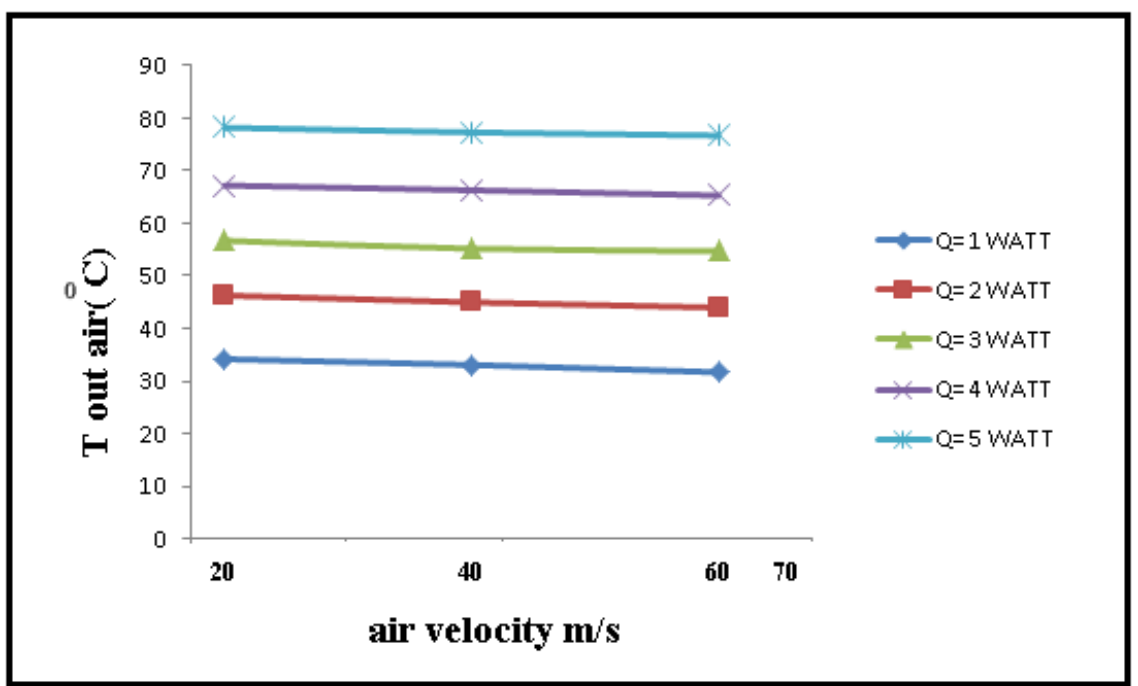

Fig. 4 The variation of air outlet temperature with inlet air velocities for several heater powers



Fig. 5 Variation of heat transfer coefficient of with inlet air velocities at different heater powers 
Journal of University of Babylon for Engineering Sciences, Vol. (26), No. (7): 2018.

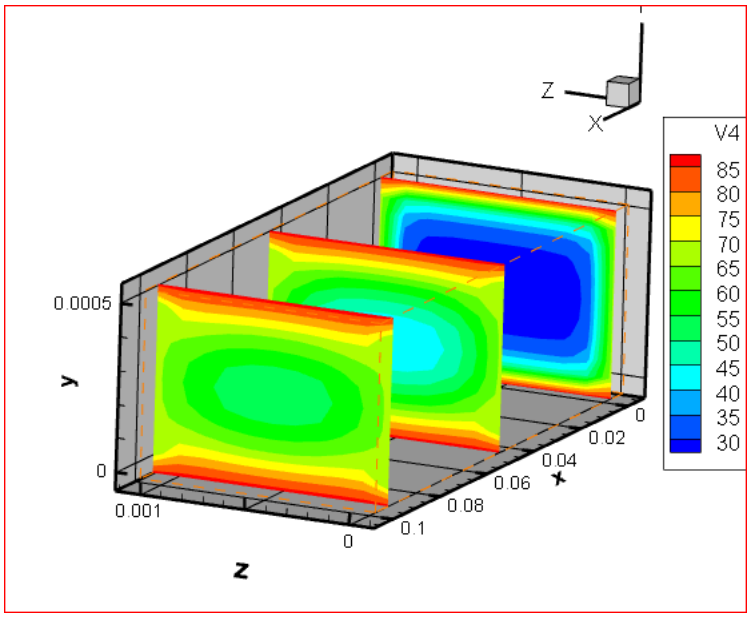

a

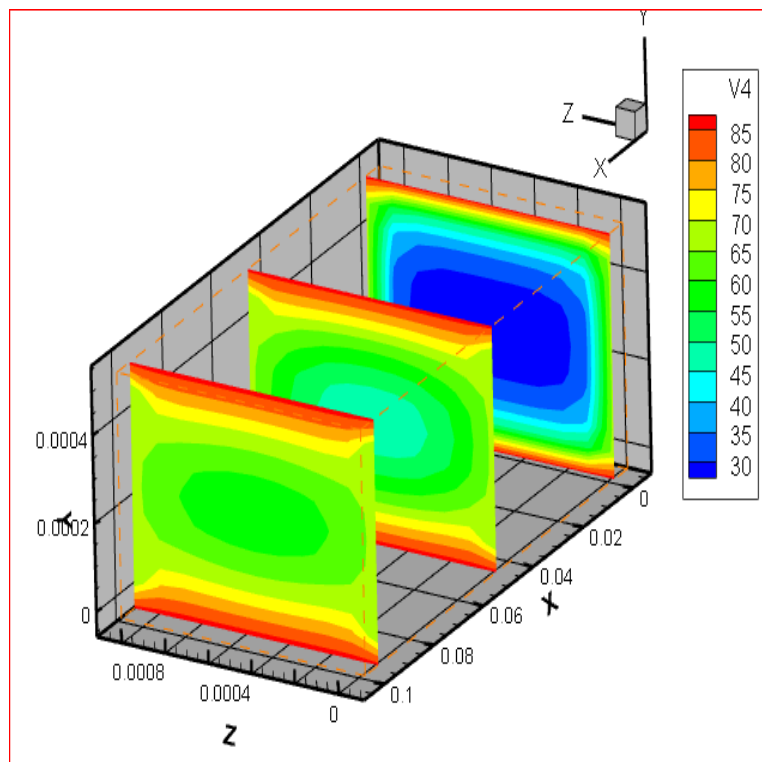

b

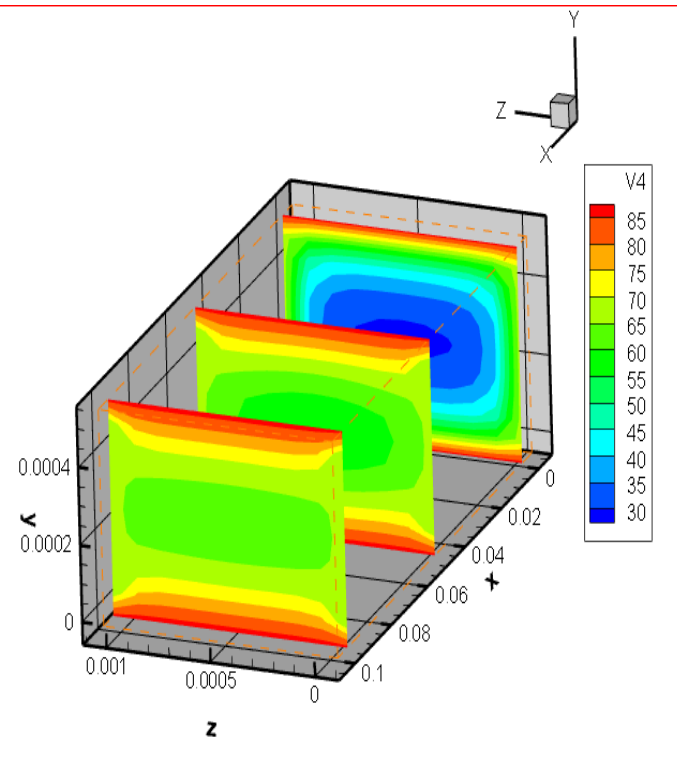

$\mathrm{C}$

Fig. 6 Isotherm contours of air through micro-channel at power $=5 \mathrm{~W}, U_{C h}=20(c), 40(b)$, $60($ a) $\mathrm{m} / \mathrm{s}$ 


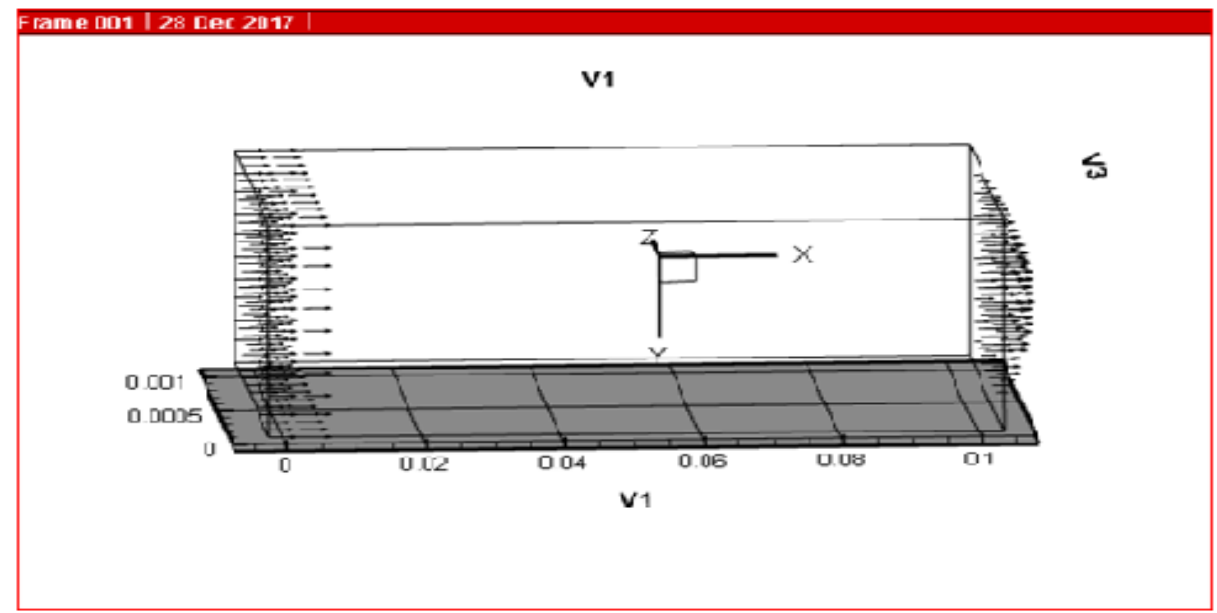

Fig. 7 Flow field of air flow through micro-channel 3D, at $U_{C h}=60 \mathrm{~m} / \mathrm{s}$

\section{References}

[1] Tuckerman, D .B. and Pease, High-performance heat sinking for VLSI. IEEE electron device letters 2, 126-129, 1981..

[2] Al-Bakhit, Hussien, and Ahmad Fakheri, "Numerical simulation of heat transfer in simultaneously developing flows in parallel rectangular ducts." Applied thermal engineering 26.5: 596-603, 2006.

[3] Bertsch, Stefan S., Eckhard A. Groll, and Suresh V. Garimella, "A composite heat transfer correlation for saturated flow boiling in small channels." International Journal of Heat and Mass Transfer52.7: 2110-2118, 2009.

[4] Mohammed H. A., Gunnasegaran P., and Shuaib N. H, "Numerical simulation of heat transfer enhancement in wavy microchannel heat sink." International Communications in Heat and Mass Transfer 38.1: 63-68., 2011.

[5] Al-Asadi, Mushtaq T., Alkasmoul F. S., and Wilson M. C. T., "Heat transfer enhancement in a microchannel cooling system using cylindrical vortex generators." International Communications in Heat and Mass Transfer 74: 40-47, 2016.

[6] Abdul-Rasool, Adnan A., Ekhlas M. Fayyadh, and Adil Abbas Mohammed. "Prediction of two-phase flow boiling characteristics in microchannels heat sink by artificial neural network." Journal of Engineering and Sustainable Development Vol 21.5, 2017.

[7] Arie, Martinus A., Amir H. Shooshtari, and Michael M. Ohadi, "Experimental characterization of an additively manufactured heat exchanger for dry cooling of power plants." Applied Thermal Engineering 129: 187-198, 2018.

[8] Kwon, Beomjin et.al., "High power density air-cooled microchannel heat exchanger." International Journal of Heat and Mass Transfer 118: 1276-1283, 2018. 
Journal of University of Babylon for Engineering Sciences, Vol. (26), No. (7): 2018.

[9] A Thesis Submitted "Thermal analysis of cooling by micro-channel with thermal electric control" to the Department of Electromechanical Engineering University Technology By Amjed Alwan Kadhim

[10] Awbi H. B., 2003, "Ventilation of buildings", Taylor $\backslash \&$ Francis, London.

[11] Cengel Y. A., Heat Transfer; A practical Approach, McCraw-Hill Education, 2003.

[12] Versteeg H. and Malalsekera W., "An Introduction to Computational Fluid Dynamics: The Finite Volume Method", Longman Group Ltd, 2007.

[13] Patankar S. V., "Numerical Heat Transfer and Fluid Flow", McGraw-Hill Book Company, 1980. 
Journal of University of Babylon for Engineering Sciences, Vol. (26), No. (7): 2018.

دراسة تجريبية وعددية لتعزيز معامل انتقال الحرارة في تدفق الهواء باستخدام القتاة الصغرى

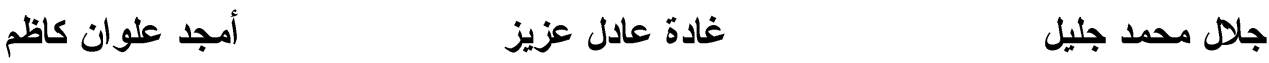

قسم الهنسسة الكهرو ميكانيكية، الجامعة التكنولوجية، بغداد، العراق

تم في هذا البحث دراسة جريان المائع(الهواء) و انتقال الحرارة في القنواة الصغرى. شملت الدراسة تغير

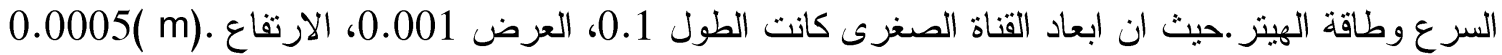
تم مقارنة النتائج العملية و النظرية في بحث سابق لغاية سرعة m/s 20 وطاقة الهيتر الذي ثنتت ابعاده بما يتناسب

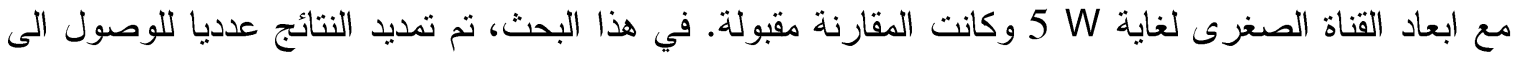
السرعة . 60(m/s) استخدم في الحل العددي طريقة الحجوم المحددة لحل معادلات) stokes-Navier

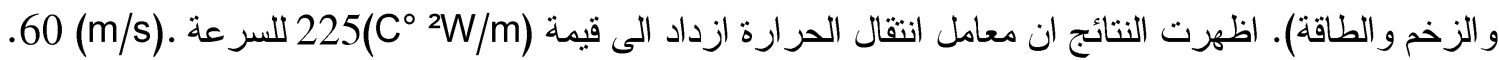

الكلمات المفتاحية: - قناة مستطيلة، قناة الصغرى، CFD، محاكاة D3، معامل نقل الحرارة. 